\title{
Energy saving policy in water distribution networks
}

\author{
M. Giugni ${ }^{1}$, N. Fontana ${ }^{2}$ and D. Portolano ${ }^{3}$ \\ ${ }^{1}$ Department of Hydraulic, Geotechnical and Environmental Engineering \\ University of Naples Federico II, Via Claudio 21, 80125 Naples (Italy) \\ phone: +39 081 7683443; fax: +39 081 5938936, e-mail: giugni@unina.it \\ ${ }^{2}$ Department of Engineering \\ University of Sannio, Piazza Roma 21, 82100 Benevento (Italy) \\ phone: +39 0824 305564, fax: +390824 325246, e-mail: fontana@unisannio.it \\ ${ }^{3}$ Centre of Environmental Research C.I.R.AM. \\ University of Naples Federico II, Via Mezzocannone 16, 80134 Naples (Italy) \\ phone: +39 081 401023, fax: +39 081 409782, e-mail: davide.portolano@unina.it
}

\begin{abstract}
In the last years, issues concerning water saving in water distribution systems have paid interest through an integrated policy aiming at reducing leakage by means of pressure control. Hence, in water distribution systems Pressure Reducing Valves (PRVs) are often used to prevent the downstream hydraulic grade from exceeding a set value. Nevertheless, PRVs must be strategically placed to maximize their effectiveness. In recent years the application of turbines or pumps operating as turbines (PATs) appeared as an alternative and sustainable solution to either control network pressure as well to produce energy. In the present paper PRVs and PATs were used to control pressure within a district of Naples water distribution network, showing large potential revenues of PATs and an attractive capital payback period.
\end{abstract}

\section{Key words}

Water distribution networks, Water leaks reduction, Energy saving policy, Pressure Reducing Valve (PRV), Pump as Turbine (PAT).

\section{Introduction}

From a recent report of the Committee for the Vigilance on the Use of Water Resources (2005), the total water losses in Italy (physical and administrative) range between $20 \div 65 \%$, with an average value around $40 \%$.

As well known, the greater share of physical leaks is localized in distribution networks: an active leakage control in order to reduce water losses would therefore concur a significant water and energy saving with economic and environmental benefits.

It is well known the pressure-leakage relationship. So the objective of any pressure control strategy should be to minimize excessive pressures as far as possible, while ensuring sufficient pressures to satisfy customer demands at all times.

As the complexity of a water distribution system grows, the task of achieving the target pressure level becomes more difficult.

Pressure reduction in water networks can be achieved in several ways. An effective pressure control can be performed by means of pressure reducing valves (PRVs) to prevent the downstream hydraulic grade from exceeding a set value. PRVs are variable closure devices that reduce the conveyance capacity of the pipe by increasing the pressure losses. Effectiveness of PRVs in water distribution systems can be maximized by strategically placing and establishing optimum settings (static or dynamic).

A different approach to control head pressures in water distribution systems is the District Meter Areas (DMAs) design [1]. A DMA is an area supplied from few water inputs, into which discharges can be easily measured to determine leaks. In DMAs an effective control of head patterns can be performed by means of PRVs.

The abovementioned approaches can effectively optimize management of water distribution systems, gaining positive effects on water losses reduction, pipe failure rates and rupture frequencies [2].

The opportunity to combine water saving with current renewable energy policies, pointed out the chance of replacing PRVs with turbines or pumps as turbines (PATs). The installation of micro-hydro $(<100 \mathrm{~kW})$ and mini-hydro $(100 \mathrm{~kW} \div 1 \mathrm{MW})$ in water distribution systems 
can represent a point of convergence between pressure control for leak reduction and energy recovering [3][4].

\section{Case study}

The present paper shows the noteworthy points of a research aimed to the hydraulic optimization of "Napoli Est" network, pertaining to the system of Water Agency ARIN S.p.A. (Neapolitan Water Resources Agency).

In greater detail, the "Napoli Est" area has a surface of about 920 hectares (nearly $8 \%$ of the Municipality of Naples) and covers most of the eastern zone of the city (Figure 1). Resident number is approximately $65.000 \div 70.000$ and the area elevation varies in the range $11 \div 78 \mathrm{~m}$ above sea-level. The network is supplied by "San Sebastiano" reservoir, with 6 tanks for a total storage volume of $30.000 \mathrm{~m}^{3}$. The reservoir maximum water depth is $5.40 \mathrm{~m}$ and the overflow elevation is $112.50 \mathrm{~m}$ above sea-level.

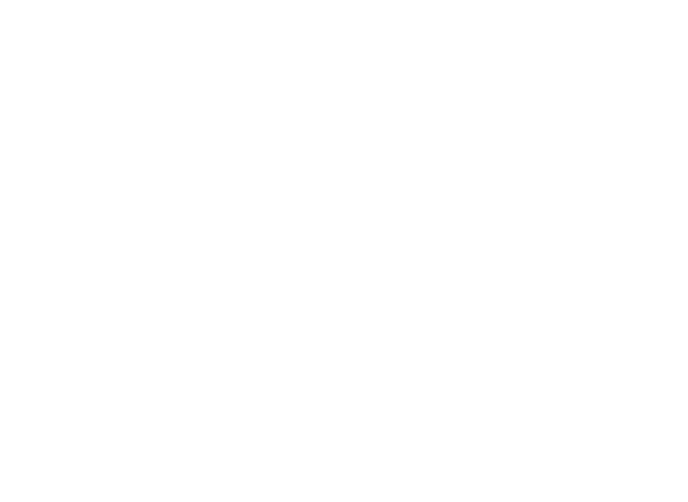

Figure 1. Location of "Napoli Est" area in the Naples Municipality.

The distribution network is heavy looped and pipes are in reinforced concrete, grey cast iron, steel and ductile cast iron, with diameters ranging from DN 40 to DN 1000. 


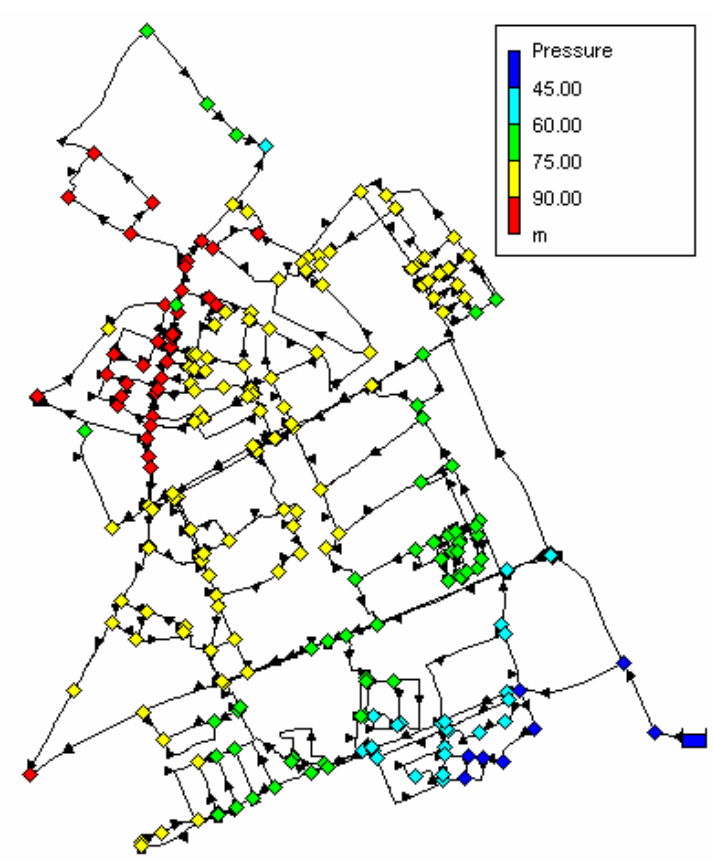

Figure 4. Pressure head at the junctions during peak hour demand in the current configuration

The following relationship exists between head pressure $P$ and physical losses $Q^{1}[5]-[8]$ :

$$
Q^{l} \quad C P
$$

being $\mathrm{C}$ and $\alpha$ coefficients varying according to pipe characteristics and type of loss. Such correlation was confirmed and emphasized by the experimental results on the "Napoli Est" distribution system.

Consequently, the water network optimisation with turbines or pumps as turbines appeared a suitable solution to achieve water losses reduction, benefits in monitoring the system water balance and remarkable energy saving.

\section{Hydraulic simulations and optimization procedure}

Hydraulic simulations were carried out using EPANET 2.0 [9]. Hydraulic layout resulted from the skeletonized network [10], eliminating out of order pipes, integrating pipelines of same diameter and roughness, replacing dead-end branches and small networks supplied by a single junction with an equivalent flow.

The water distribution system is constituted by 100 meshes, 259 junctions and 358 pipes. Daily pattern of water levels in the tank were assigned from measured levels during the field measurement campaign, whereas node daily demand was estimated from billed consumptions.

Physical losses were distributed among all the system nodes (supplying nodes and leaking nodes). The following relationships were adopted to evaluate the supplied flows $\mathrm{q}_{\mathrm{tj}}$ in the generic node $\mathrm{j}$, at the instant $\mathrm{t}$ :

- supplying node: $q_{t j} \quad c_{t} \overline{q_{j S U P}} \quad C \quad p_{t j}$
- $\quad$ leaking node (emitters): $q_{t j} \quad C p_{t j}$

where $\mathrm{q}_{\mathrm{sup}}=$ total flow and apparent losses; $\mathrm{c}_{\mathrm{t}}=$ hourly coefficient; $C, \alpha=$ emitter coefficient and emitter exponent (see eq. (1)).

According to the literature [6], it was assumed $\alpha=0.80$. Coefficient $\mathrm{C}$ was assumed constant for all nodes, and network calibration returned $\mathrm{C}=0.02$. Calibration returned as well reliable pipe roughness coefficients, thus allowing a consistent simulation of the average daily pattern, given in Figure 5 [11].

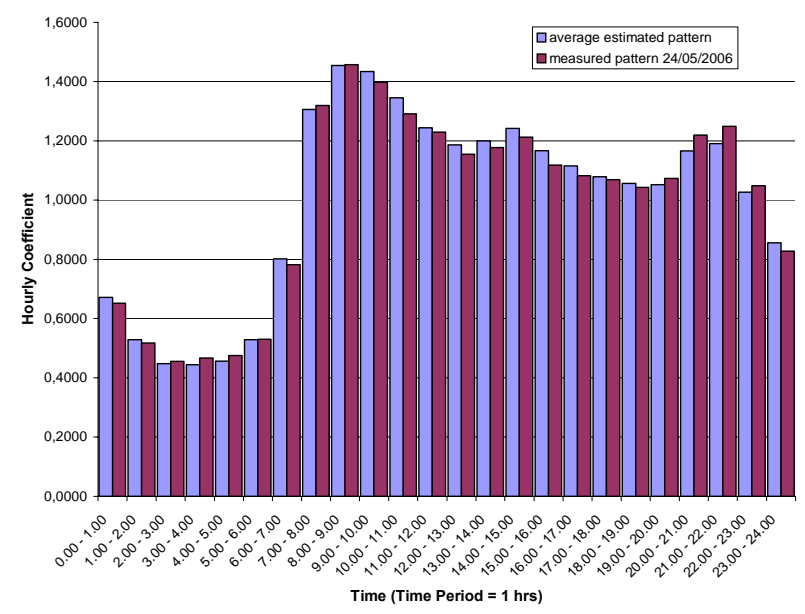

Figure 5. Consumption daily pattern.

After network calibration, several scenarios aiming at reducing physical losses were preliminarily analyzed by using PRVs.

Optimization was implemented by means of PIKAIA Genetic Algorithm (GA) [12] supported by NITSOL algorithm [13] used as hydraulic solver. GAs are robust search methods that seek to reproduce mathematically the mechanism of natural selection and population genetics, according to the biological processes of survival and adaptation [14]. GAs improve upon an initial population of strings representing a set of possible solutions generated randomly. The repeated application of genetic operators searchers allows efficient solutions to the problem at hand. Those with higher objective function (or fitness function) values are retained, whereas weaker ones are discarded. Since 5-6 story buildings are located in the area, a minimum head pressure of $25 \mathrm{~m}$ was guaranteed during peak hour.

Six scenarios (A to $\mathrm{F}$ ) were analyzed, varying number and location of PRVs. Increasing water savings were obtained at increasing PRV number, as showed in Table 2. 


\begin{tabular}{|c|c|c|c|c|}
\hline \multirow{2}{*}{ Scenario } & \multirow{2}{*}{$\begin{array}{c}\text { Number of } \\
\text { PRVs }\end{array}$} & $\begin{array}{c}\text { System I nput } \\
\text { Volume }\end{array}$ & Physical leaks & $\begin{array}{c}\text { Physical leaks } \\
\text { reduction }\end{array}$ \\
\cline { 3 - 5 } & & [l/ s] & [l/ s] & [\% ] \\
\hline O & 0 & 340,2 & 157,6 & - \\
\hline A & 1 & 323,7 & 141,1 & $10,5 \%$ \\
\hline B & 2 & 321,4 & 138,7 & $12,0 \%$ \\
\hline C & 3 & 307,0 & 124,4 & $21,1 \%$ \\
\hline D & 4 & 303,3 & 120,6 & $23,5 \%$ \\
\hline E & 5 & 301,1 & 118,4 & $24,8 \%$ \\
\hline F & 6 & 295,2 & 112,6 & $28,5 \%$ \\
\hline
\end{tabular}

Table 2. Results of hydraulic optimization.

\section{Energy production by means of turbines or pumps as turbines (PATs)}

The opportunity to combine water saving with current renewable energy policies, pointed out the chance of replacing (in part or at all) PRVs with turbines or pumps as turbines (PATs).

Turbine fitting in water networks is an unusual application requiring preliminary analysis to guarantee: optimal choice of the turbine; sufficient network pressure; suitable sanitary conditions; protection against potential pipes damage due to water hammer effects. In particular, water hammer effects should be evaluated in normal operating conditions and in specific states as starting and electric shedding, in order to protect distribution system with adequate devices.

Optimal turbine design should account for daily and seasonal patterns of demand and pressures, which dramatically modify turbine operation. On-line installed turbines can be reaction turbines or PATs. Reaction turbines are optimized for the specific installation, but their use may be really expensive. PATs are less expensive and largely available and they should be accurately selected to obtain higher performance and efficiency as possible.

When operating in reverse, standard pumps have important advantages over conventional turbines for small-scale hydropower generation [15]: mass production of pumps, whereas turbines are designed for each site; integral pump and motor can be purchased and used as a turbine-generator unit; available for a wide range of heads and flows; available in large number of sizes; low cost; short delivery time; spare parts are easily available; easy installation. Nevertheless, PATs main limitation is the range of flow rates over which unit can operate, which is much smaller than in a conventional turbine.

Pump performance curves show the relation between head and flow delivered by the pump. As flow increases, delivery head decreases. It is important to know the point at which the pump works most efficiently. The maximum efficiency varies according to the type and size of pump, usually $40 \%$ to $80 \%$ and it detects the pump best efficiency point (BEP).
In turbine mode, the flow increases with increasing head. The characteristic curves of PATs can be calculated according to the experiments of some researchers [16], resulting in the following relationship between pump and PAT BEP:

$$
\begin{aligned}
& Q_{t 1} \quad \frac{Q_{p b}}{p b}, H_{t 1} \quad \frac{H_{p b}}{p b} \\
& \frac{H_{t b}}{H_{t 1}} \quad \frac{N_{t}}{N_{p}} \quad, \frac{Q_{t b}}{Q_{t 1}} \quad \frac{N_{t}}{N_{p}}
\end{aligned}
$$

where $\mathrm{Q}=$ flow rate $\left(\mathrm{m}^{3} / \mathrm{s}\right), \mathrm{H}=$ head $(\mathrm{m}), \mathrm{N}=$ rotational speed (rpm), $\eta=$ efficiency. Subscripts $p, t$ and $b$ refer to pump, PAT and BEP. Subscript 1 refers to pump and PAT at the same rotational speed.

According to experimental data, PAT and pump BEPs were supposed equal [17]. Consequently PAT power $\mathrm{P}_{t b}$ (W) at BEP was calculated as follow:

$$
P_{t b} \quad g Q_{t b} \quad H_{t b} \quad{ }_{t b}
$$

where $\rho$ and $g$ are fluid density and gravitational acceleration.

A PAT may work at off-design conditions, but most prediction methods only predicted the BEP of the PAT. Therefore, estimating the complete characteristic curves of a PAT based on its BEP is very remarkable. In this case the following experimental relationships were used [17], valid for centrifugal pumps with specific speeds $\mathrm{N}_{\mathrm{s}}$ between 14 to $60\left(\mathrm{~m}, \mathrm{~m}^{3} / \mathrm{s}\right)$ :

$$
\begin{array}{cccc}
\frac{H_{t}}{H_{t b}} & 1.0283 \frac{Q_{t}}{Q_{t b}} & 0.5468 \frac{Q_{t}}{Q_{t b}} & 0.5314 \\
\frac{P_{t}}{P_{t b}} & 0.3092 \frac{Q_{t}}{Q_{t b}} & 2.1472 \frac{Q_{t}}{Q_{t b}} \\
& 0.8865 \frac{Q_{t}}{Q_{t b}} & 0.0452
\end{array}
$$

\section{PATs installation in water distribution system}

In the present section preliminary results obtained on "Napoli Est" water distribution were given. PRVs were coupled or replaced by PATs, aiming at joining pressure control and energy recovery. For the sake of brevity, only scenarios A, B and D (see Table 2) were analyzed.

\begin{tabular}{|c|c|c|c|c|}
\hline \multirow{2}{*}{ Pump } & Qpb & $\mathrm{Hpb}$ & $\eta p b$ & Ppb \\
\hline & {$[\mathrm{mc} / \mathrm{s}]$} & [m] & [\%] & {$[\mathrm{kW}]$} \\
\hline NC 100-200 & 0,04 & 13,07 & $79 \%$ & 6,40 \\
\hline NC 150-200 & 0,10 & 12,20 & $80 \%$ & 14,91 \\
\hline \multirow{2}{*}{ PAT } & Qtb & $\mathrm{Htb}$ & $\eta$ tb & Ptb \\
\hline & [mc/s] & [m] & [\%] & {$[\mathrm{kW}]$} \\
\hline NC $100-200$ & 0,05 & 19,81 & $79 \%$ & 7,82 \\
\hline NC $150-200$ & 0,13 & 18,22 & $80 \%$ & 18,27 \\
\hline
\end{tabular}

Two different pumps were selected, depending on flow rate and head loss. Pumps and PATs characteristics (Caprari catalogue, 2008) obtained by eqs. (4)-(6) are given in Table 3. For all pumps rotational speed $\mathrm{N}=1450$ rpm.

Table 3. Pumps and PATs characteristic curves (Caprari, 2008). 
For the selected pumps $\mathrm{N}_{\mathrm{s}}=40$ and $70\left(\mathrm{~m}, \mathrm{~m}^{3} / \mathrm{s}\right)$, so for a preliminary analysis eqs. (6)-(8) were used to obtain PATs characteristics curves (Figs 6 and 7). Since flow directions in PATs and pumps are opposite, the flow rate of PATs is negative.

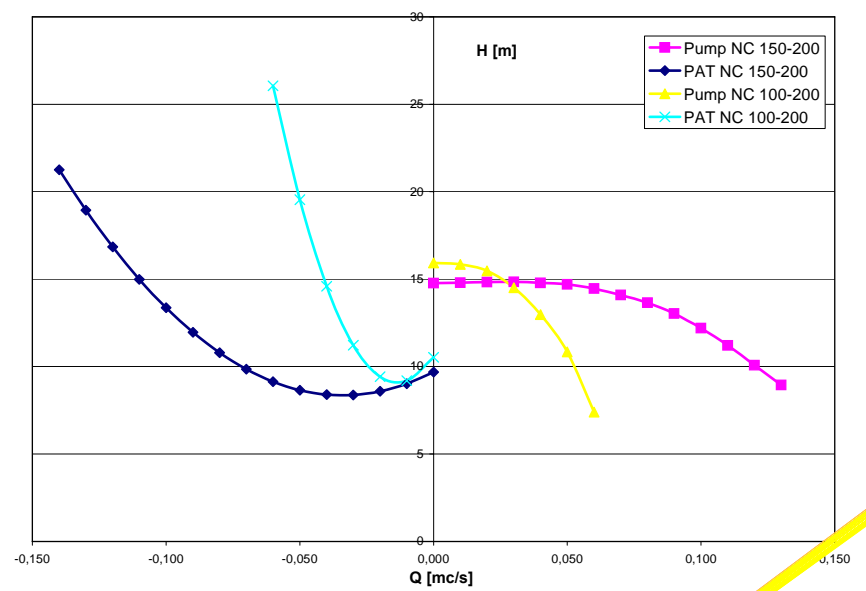

Figure 6. Head curves in pump and turbine modes.

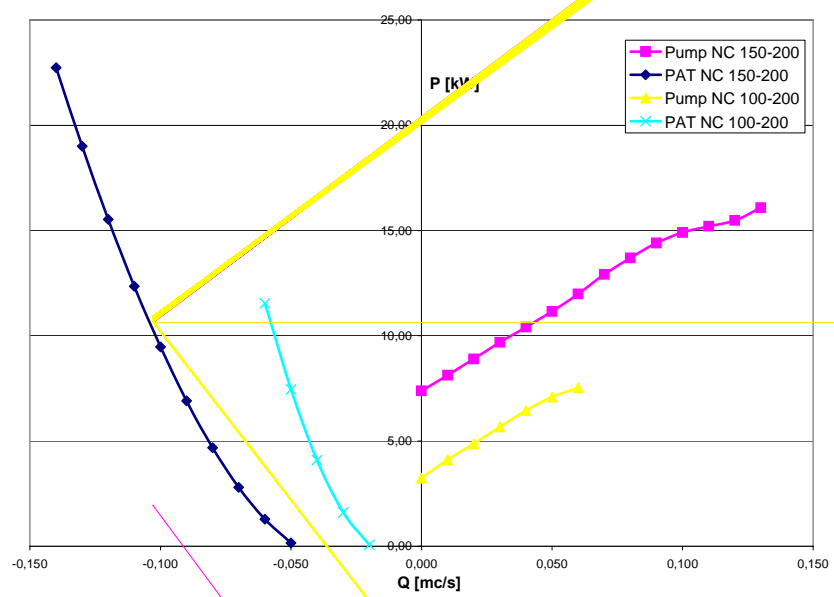

Figure 7. Power curves in pump and turbine modes.

EPANET software allowed to simulate turbine using GPV (General Purpose Valve) with PATs characteristic curves of Figure 6.

Within scenario A, the PRV located on the reservoir exit pipe was replaced by a PAT installed in the same section. Since high flows (up to $0.4 \mathrm{~m}^{3} / \mathrm{s}$ ) and small head losses, 3 parallel PATs (mod. NC 150-200) were used.

Within scenario B, the 2 PRVs were replaced by 2 PATs (mod. NC 100-200 and NC 150-200) installed in the same PRVs sections.

Lastly, within scenario D, only 2 of 4 PRVs were replaced by PATs. In greater detail, 3 parallel PATs (mod. NC 150-200) and one PAT (mod. NC 100-200) were installed, leaving unchanged the remaining 2 PRVs. A sketch of analyzed configurations is given in Figure 8. 
$1.500 €$ per installed power $\mathrm{kW}$ [18].. Civil works and devices costs were estimated $30 \%$ of pumps costs, whereas maintenance cost was estimated $15 \%$ of total installation cost.

Revenues were calculated according to Financial Italian Law, which guarantees a sale price of $220 €$ per MWh when $\mathrm{P}<1 \mathrm{MW}$.

Preliminary analysis for scenarios A, B and D is given in Tables 5 and 6 , resulting, in all cases, a really attractive capital payback period, equal to about 2.5 years for scenarios A and B and to about 3 years for scenario D.

\begin{tabular}{|c|c|c|c|c|c|c|c|}
\hline Scenario & PATs & \multicolumn{2}{|c|}{$\begin{array}{c}\text { PATs costs } \\
{[€]}\end{array}$} & \multicolumn{2}{|c|}{$\begin{array}{c}\text { Civil works and } \\
\text { devices costs } \\
{[€]}\end{array}$} & \multicolumn{2}{|c|}{$\begin{array}{c}\text { Total installation } \\
\text { costs } \\
{[€]} \\
\end{array}$} \\
\hline $\mathbf{A}$ & 3 NC 150-200 & $€$ & $90.000,00$ & $€$ & $27.000,00$ & $€$ & $117.000,00$ \\
\hline \multirow{2}{*}{ B } & 1 NC $150-200$ & $€$ & $30.000,00$ & $€$ & $9.000,00$ & \multirow{2}{*}{$€$} & \multirow{2}{*}{$56.550,00$} \\
\hline & 1 NC $100-200$ & $€$ & $13.500,00$ & $€$ & $4.050,00$ & & \\
\hline \multirow{2}{*}{ D } & 3 NC 150-200 & $€$ & $90.000,00$ & $€$ & $27.000,00$ & \multirow{2}{*}{$€$} & \multirow{2}{*}{$134.550,00$} \\
\hline & 1 NC $100-200$ & $€$ & $13.500,00$ & $€$ & $4.050,00$ & & \\
\hline
\end{tabular}

Table 5. Preliminary costs analysis.

\begin{tabular}{|c|c|cc|cc|cc|}
\hline Scenario & $\begin{array}{c}\text { Energy } \\
\text { production } \\
\text { [MWh/year] }\end{array}$ & $\begin{array}{c}\text { Maintenance } \\
\text { cost } \\
{[€ / \text { year] }}\end{array}$ & $\begin{array}{c}\text { Annual revenue } \\
\text { [€/year] }\end{array}$ & $\begin{array}{c}\text { Annual income } \\
\text { [€/year] }\end{array}$ \\
\hline A & 300,1 & $€$ & $17.550,00$ & $€$ & $66.018,11$ & $€$ & $48.468,11$ \\
\hline B & 153,0 & $€$ & $8.482,50$ & $€$ & $33.652,69$ & $€$ & $25.170,19$ \\
\hline D & 284,4 & $€$ & $20.182,50$ & $€$ & $62.565,30$ & $€$ & $42.382,80$ \\
\hline
\end{tabular}

Table 6. Preliminary incomes analysis.

Nevertheless the above given analysis is really preliminary. A detailed economic plan should consider actual installation and maintenance costs and, if necessary, protection devices costs.

\section{Conclusions}

Pumps as turbines (PATs) can be used in water distribution systems to join pressure control and energy saving. PATs can be an attractive solution integrative to PRVs installation whenever a fine downstream pressure control is not required. A simulation model based on a Genetic Algorithm was initially developed to locate PRVs and optimize water system performance. PRVs were further substituted by PATs in order to allow renewable energy production.

Preliminary economic analysis for PATs installation was also developed, showing similar leak reduction and really attractive profits and capital payback period. Obviously, results of numerical simulations are only preliminary, and they should be confirmed by monitoring one or more PATs, comparing numerical simulations with field measurements.

\section{References}

[1] Cheong L.C., International report on unaccounted for water and economics of leak detection, IWA World Conference, Budapest, 1993.
[2] Giugni M., Fontana N., Romanelli D., Portolano D., Strategic planning optimization of "Napoli Est" water distribution system, Proceeding of the XXXII Congress of IAHR, Venice (Italy), 2007.

[3] Artina S., Naldi G., Marchi A., Bragalli C., Lenzi C., Liserra T., Dal controllo della pressione al recupero energetico nei sistemi di distribuzione idrica, Proceedings of the XXXI Italian National Hydraulic Congress, Perugia (Italy), 2008 (in Italian).

[4] Portolano D., Il controllo delle perdite nei sistemi acquedottistici: criteri innovativi di gestione, $\mathrm{PhD}$ Dissertation, University of Naples Federico II, 2008 (in Italian).

[5] Khadam M. A., Shammas N. K., Al Feraiheedi Y., Water losses from Municipal Utilities and their Impacts, Water International, n. 16, 1991.

[6] Khaled H., Sendil U., Relationship between pressure and leakage in a water distribution network, Proceeding of the AWWA Conference, 1992.

[7] Lambert A., What do we know about PressureLeakage Relationship in Distribution Systems, Proceeding of the AWWA Conference on System Approach to Leakage Control and Water Distribution Systems Management, 2000.

[8] Milano V., Dipendenza delle perdite di una tubazione dalla pressione di esercizio, L'Acqua, $\mathrm{n}$. 4, 2006 (in Italian).

[9] Rossman L.A., Epanet 2, User manual, U.S. Environmental Protection Agency, Cincinnati, OH45268, EPA/600/R-00/057, 2000.

[10] Hamberg D., Shamir U., Schematic Models For Distribution Systems Design, Journal of Water Resources Planning and Management ASCE 114(2) 129-141, 1988.

[11] May J., Pressure dependent leakage, World Water and Environmental Engineering, 1994.

[12] Charbonneau P., Knapp B., A user's guide to PIKAIA 1.0, NCAR (National Center for Atmospheric Research) Technical Note, Boulder, Colorado, 1995.

[13] Pernice M., Walker H.F., NITSOL: A Newton iterative solver for nonlinear systems, SIAM (Society for Industrial and Applied Mathematics) vol. 19, No. 1, pp. 302-318, January 1998.

[14] Goldberg D.E., Genetic algorithms in search, optimization and machine learning, AddisonWesley Publishing Co., 1989.

[15] Isbasoiu E.C., Bucur D.M., Ghergu C.M., Dunca G., Using standard pumps as turbines, CEEX Conference, 2007.

[16] Williams A., Pumps as turbines: a user's guide, Intermediate Technology Pub. Ltd., London, 1995.

[17] Derakhshan S., Nourbakhsh A., Experimental study of characteristic curves of centrifugal pumps working as turbines in different specific speeds, Experimental thermal and fluid science 32, 2008.

[18] ESTIR Resource, indicators_111_small_ hydropower_sep2002.pdf, 2002. 